\title{
Esophageal Hiatus Hernia
}

\author{
Meng-You Zeng ${ }^{1,2}$, Xiao-Fei Fan ${ }^{1,2}$, Wei Liu ${ }^{1,2^{*}}$ \\ ${ }^{1}$ Institute of Digestive Disease, China Three Gorges University, Yichang, China \\ ${ }^{2}$ Department of Gastroenterology, Yichang Central People's Hospital, Yichang, China
}

^Correspondence to: Wei Liu; Institute of Digestive Disease, China Three Gorges University, 8 Daxue Road, Yichang 443000, China; E-mail: liuwei@ctgu.edu.cn

Received: Dec 19 $9^{\text {th }}, 2020$; Accepted: Dec 22 ${ }^{\text {nd }}, 2020$; Published: Dec 27 $7^{\text {th }}, 2020$

Citation: Zeng M-Y, Fan X-F, Liu W. Esophageal hiatus hernia. Gastro Open A Open J. 2020; I(1): 26. doi: 10.33169/gastro.GOAOJ-I-106

\section{INTRODUCTION}

A 83-year-old women presented to the emergency department with epigastric pain and vomiting that had progressively worsened over a period of 1 year. Her medical history was notable for type 2 diabetes and hypertension. A physical examination revealed that breath sounds were weakened. Her abdomen was soft, with moderate epigastric tenderness and normal bowel sounds. The rest of the physical examination was unremarkable. A radiograph of the chest confirmed compression of both lungs for unknown reasons (Figure 1A). Computed tomography (CT) of the chest revealed a large hiatus hernia containing almost the entire stomach (Figure 1B). A diagnosis of esophageal hiatus hernia was made. Hiatus hernia refers to a disease status involving herniation of the contents of the abdominal cavity, especially the stomach, through esophageal hiatus of the diaphragm into the mediastinum. ${ }^{1-3}$ It is accepted that the prevalence of hiatus hernia increases with age and body mass index. ${ }^{4,5}$ The typical symptom of hiatus hernia is gastroesophageal reflux and less common symptoms are epigastric or chest pain and dysphagia. ${ }^{3,6,7}$ It is necessary to make a critical risk-benefit assessment mandatory before complicated and surgical treatment of hiatus hernia, usually coupled with an antireflux procedure. ${ }^{8,9}$ After a well-informed discussion of treatment options with the patient and her family, the decision was made to pursue surgery. After the procedure, she clinically improved and was discharged home with outpatient follow-up.

Figure 1. Esophageal Hiatus Hernia. (A) Orthotopic chest radiograph; (B) axial CT image of a hiatus hernia (arrows).
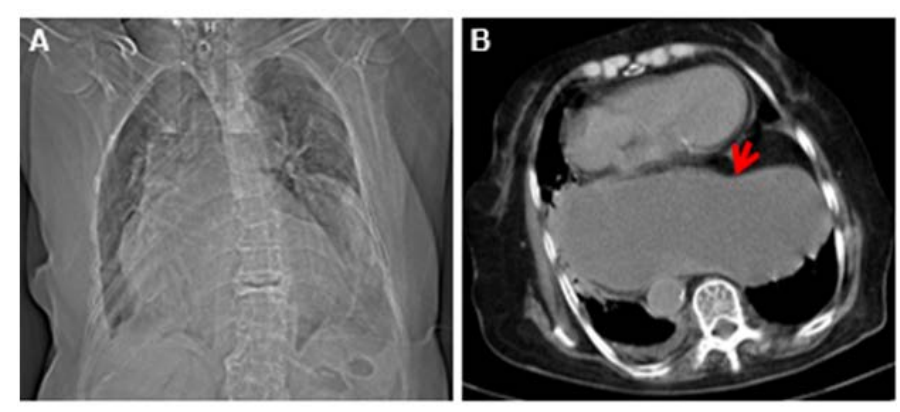

\section{FUNDING}

This work was supported by National Natural Science Foundation of China (31600134).

\section{ETHICAL STATEMENT}

The authors are accountable for all aspects of the work in ensuring that questions related to the accuracy or integrity of any part of the work are appropriately investigated and resolved. Written informed consent was obtained from the patient for publication of this "Images in Clinical Medicine".

\section{CONFLICTS OF INTEREST}

None.

\section{REFERENCES}

1. Roman S, Kahrilas PJ. The diagnosis and management of hiatus hernia. BMJ. 2014; 349: g6154. doi: 10.1136/bmj.g6154

2. Menon S, Trudgill N. Risk factors in the aetiology of hiatus hernia: a meta-analysis. Eur J Gastroenterol Hepatol. 2011; 23(2): 133-138. doi: 10.1097/meg.0b013e3283426f57

3. Kohn GP, Price RR, DeMeester SR, et al. Guidelines for the management of hiatal hernia. Surg Endosc. 2013; 27(12): 4409-4428. doi: 10.1007/s00464-013-3173-3

4. Dean C, Etienne D, Carpentier B, Gielecki J, Tubbs SR, Loukas M. Hiatal hernias. Surg Radiol Anat. 2012; 34(4): 291-299. doi: 10.1007/ s00276-011-0904-9

5. Wilson LJ, Ma W, Hirschowitz BI. Association of obesity with hiatal hernia and esophagitis. Am J Gastroenterol. 1999; 94(10): 2840-2844. doi: 10.1111/j.1572-0241.1999.01426.x

6. Pandolfino JE, Kwiatek MA, Ho K, Scherer JR, Kahrilas PJ. Unique features of esophagogastric junction pressure topography in hiatus hernia patients with dysphagia. Surgery. 2010; 147(1): 57-64. doi: 10.1016/j. surg.2009.05.011

7. Hyun JJ, Bak YT. Clinical significance of hiatal hernia. Gut Liver. 2011; 5(3): 267-277. doi: 10.50092Fgnl.2011.5.3.267

8. Allaix ME, Patti MG. Laparoscopic paraesophageal hernia repair. Surg Laparosc Endosc Percutan Tech. 2013; 23(5): 425-428.

9. Poulose BK, Gosen C, et al. Inpatient mortality analysis of paraesophageal hernia repair in octogenarians. J Gastrointest Surg. 2008; 12(11): 1888-1892. doi: 10.1007/s11605-008-0625-5 